
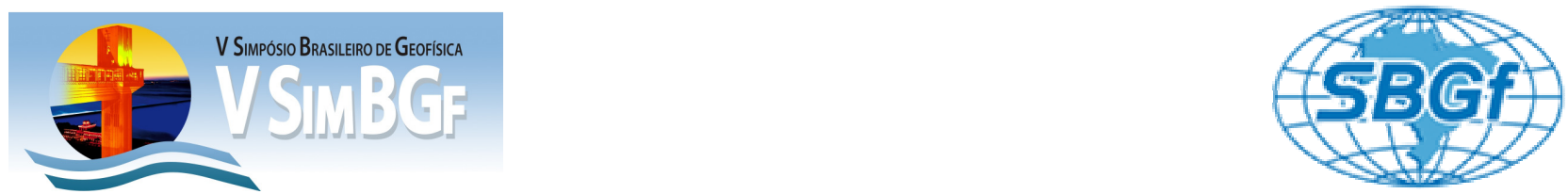

\title{
INTERPRETAÇÃO SÍSMICA 2-D E MODELAGEM GEOLÓGICA-GEOFÍSICA 2,5-D DE UMA ÁREA DA BACIA DO PARNAÍBA
}

\author{
Adriane Gomes Pinheiro (UFPA), João Carlos Ribeiro Cruz (*) (UFPA) e Pedro Andrés Chira Oliva (UFPA)
}

Copyright 2012, SBGf - Sociedade Brasileira de Geofísica

Este texto foi preparado para a apresentação no V Simpósio Brasileiro de Geofísica, Salvador, 27 a 29 de novembro de 2012. Seu conteúdo foi revisado pelo Comitê Técnico do V SimBGf, mas não necessariamente representa a opinião da SBGf ou de seus associados. É proibida a reprodução total ou parcial deste material para propósitos comerciais sem prévia autorização da SBG.

\section{Resumo}

A Bacia do Parnaíba é uma bacia paleozóica intracratônica localizada na região nordeste ocidental brasileira. Esta bacia encontra-se em um estágio exploratório preliminar com pouca expectativa no âmbito de exploração de petróleo, contudo as informações disponíveis indicam que ela possui as condições básicas para a ocorrência de acumulações de hidrocarbonetos. Neste contexto, o presente trabalho apresenta os resultados da interpretação de dados sísmicos bidimensional (2-D) que fazem parte de um projeto da Agência Nacional do Petróleo, Gás Natural e Biocombustíveis (ANP) tendo como objetivo avaliar o potencial petrolífero desta bacia. Para a interpretação sísmica contamos com o auxílio da interpretação do perfil composto de um poço, a partir da calibração sísmicapoço, e do mapa geológico da área. Ao todo, foram mapeados dez refletores a partir do topo da Formação Piauí até o nível do embasamento. A partir do mapeamento dos refletores podem-se observar algumas regiões que sugerem ser depocentros, as quais devem estar relacionadas ao lineamento Transbrasiliano, principal lineamento regional desta bacia. Finalmente, é apresentado um modelo em profundidade 2,5-D das estruturas geológicas existentes na área de estudo com destaque para as Formações Pimenteiras (unidade potencialmente geradora) e Cabeças (unidade potencialmente reservatória), contribuindo para estudos no âmbito da geologia do petróleo na Bacia do Parnaíba e servindo para a simulação de experimentos sísmicos.

\section{Introdução}

O presente trabalho tem como objetivo interpretar linhas sísmicas da Bacia do Parnaíba e fazer uma modelagem geológica e geofísica $2,5-D$ da seção sísmica mais representativa e de melhor qualidade dentre as linhas sísmica interpretadas. A interpretação sísmica foi feita a partir da calibração sísmica-poço. Com o auxílio da interpretação do perfil composto de um poço e do mapa geológico da área, foi possível fazer uma correlação entre os dados dos perfis do poço com os refletores que aparecem na linha sísmica, e assim realizar um mapeamento mais preciso do que do que se mostrou visível na malha sísmica. A Bacia do Parnaíba pertence ao grupo de bacias paleozóicas brasileiras que são áreas extensas inteseridas nas antigas regiões cratônicas. A Bacia do Parnaíba está localizada na Província Estrutural Parnaíba, na parte nordeste ocidental do território brasileiro (Figura 1). Encontra-se inserida na plataforma Sul-Americana sobreposta a um embasamento cristalino cratonizado após o término do evento Brasiliano.

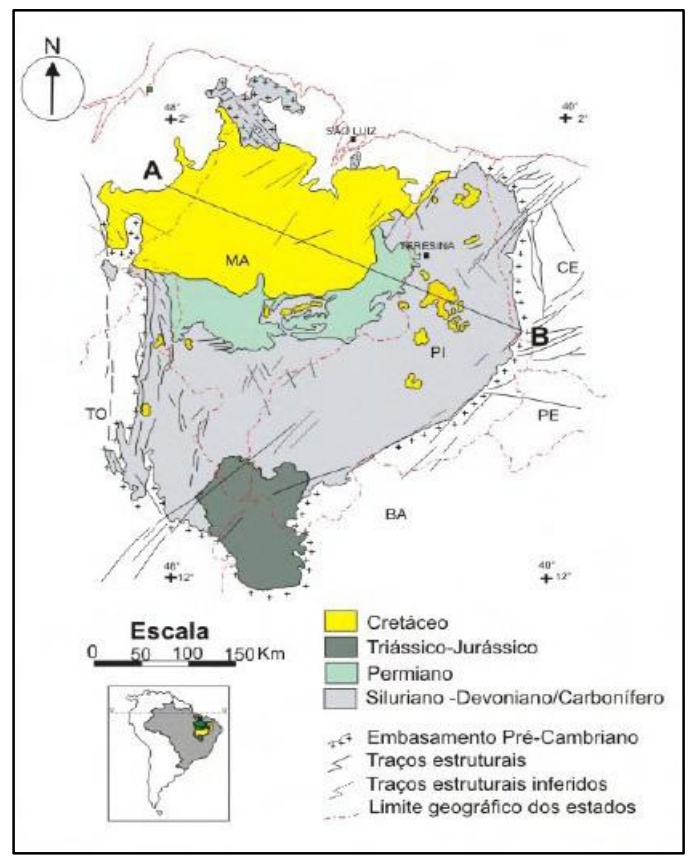

Figura 1. Mapa de localização e enquadramento estrutural da bacia doParnaíba(modificado de Serviço Geológico do Brasil -CPRM, 2002).

Segundo o proposto de Góes e Feijó (1994), a Bacia do Parnaíba está representada apenas por rochas paleozóicas, correspondentes aos grupos Serra Grande, Canindé e Balsas, que tiveram um desenvolvimento tectônico e sedimentar associado à subsidência do embasamento da bacia dentro do contexto evolutivo do paleo-continente Gondwana. O desenvolvimento tectonosedimentar da Bacia do Parnaíba é atribuído à estruturação precursora relacionada aos pulsos terminais do Ciclo Brasiliano (cerca de 500Ma), responsável pela formação de grábens (Figura 2) distribuídos por toda a bacia, com eixos orientados de nordeste a norte. A influência desta tectônica no desenvolvimento da sedimentação pós-ordoviciana marcou pronunciadamente as primeiras fases deposicionais na bacia. A Bacia do 
Parnaíba encontra-se em um estágio exploratório preliminar, contudo as informações disponíveis indicam que ela possui as condições básicas para a ocorrência de acumulações de hidrocarbonetos. A Formação Pimenteiras é considerada a principal unidade potencialmente geradora de hidrocarbonetos, distribuindose amplamente e alcançando espessuras superiores a $500 \mathrm{~m}$. Os principais reservatórios são os arenitos devonianos da Formação Cabeças capeados por folhelhos devonianos.

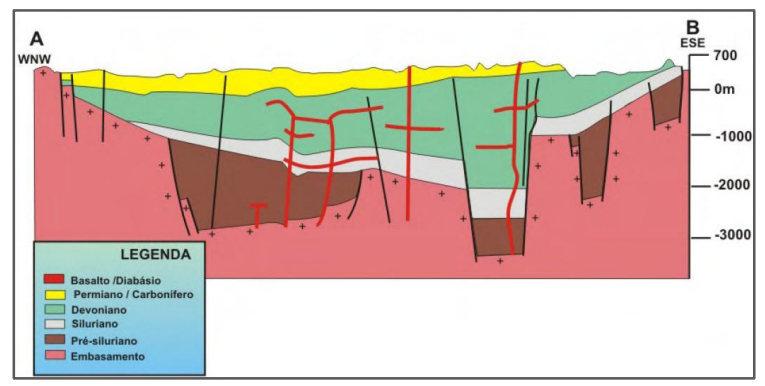

Figure2. Seção geológica (A-B) esquemática da Bacia Parnaíba Fonte: Góes et al. (1994), modificado.

\section{Metodologia}

Este trabalho foi realizado em duas etapas: Interpretação sísmica e modelagem geológica-geofísica 2,5D. As seis linhas sísmicas 2D utilizadas para a interpretação fazem parte de um projeto da Agência Nacional do Petróleo, Gás Natural e Biocombustíveis (ANP) que recebeu o nome de 0295_ANP_2D_PARNAIBA (Figura 3), com o objetivo de avaliar o potencial petrolífero da Bacia do Parnaíba. Esta malha sísmica acompanha a trajetória dip e strike do lineamento estrutural Transbrasiliano, principal lineamento regional desta bacia. Uma das linhas foi estrategicamente planejada para passar sobre o poço 1FL-1-PI para que houvesse uma melhor integração dos dados e assim possibilitar uma interpretação sismoestratigráfica dos horizontes sísmicos correspondentes à geologia da área. Este conjunto de dados foi adquirido da ANP pelo Instituto de Geociências da Universidade Federal do Pará (IG-UFPA) para fins de desenvolvimento acadêmico.

A interpretação sísmica apresentada a seguir foi possível após a calibração do poço 1-FL-1-P1 com a Linha 0295_0009 feita por Teixeira (2010). Conforme mostrado na Figura 4, Teixeira (2010) define que os horizontes mais marcados na sísmica representavam as formações observadas na interpretação do perfil composto do Poço 1-FL-1-PI .No trecho da Linha 0295-0009 (migrada pósstack) que passa pelo poço 1-FL-1-P1 foram marcados oito horizontes sísmicos através dos picos no perfil de Raios Gama (vermelho) e no perfil Sônico (Verde), conforme mostrado na Figura. Os oito horizontes marcados representando 0 topo das seguintes Formações, na ordem da base para o topo: Embasamento (vermelho), Formação Ipu (laranja), Formação Jaicós (azul marinho), Formação Itaim (rosa claro), um refletor muito marcante de idade Devoniano Médio (amarelo), Formação Pimenteiras (azul claro),
Formação Cabeças (rosa-pink) e Formação Longá (verde).

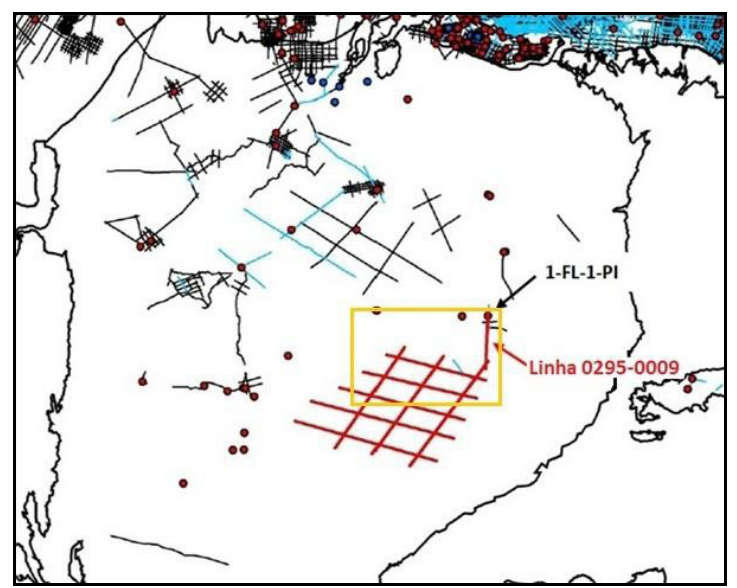

Figura 3: Mapa esquemático mostrando o esforço exploratório na Bacia do Parnaíba, com as nove linhas sísmicas do projeto 0295_ANP_2D_PARNAIBA (em vermelho). As setas indicam a localização do poço 1-FL1-P1 e da linha 0295-0009 que passa por este poço.

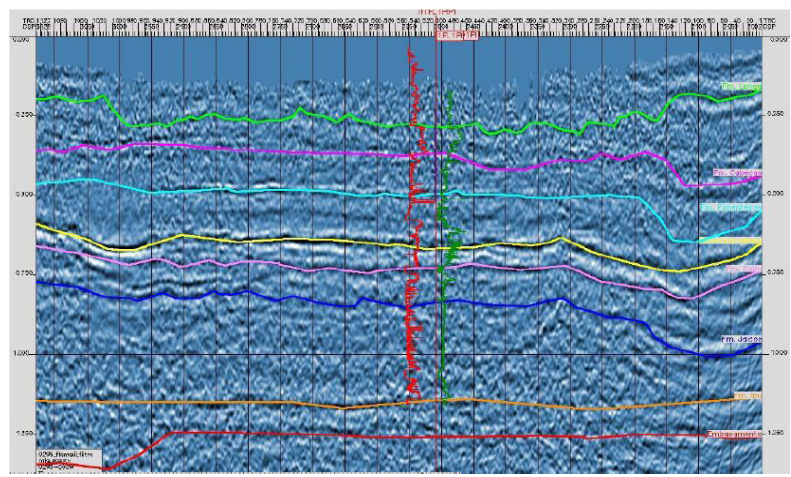

Figura 4: Snapshot tirado do programa GeoFrame mostrando a interpretação do perfil de Raios Gama (vermelho) e Perfil Sônico (Verde) nos horizontes mais marcantes observados no trecho da Linha 0295-0009 que passa pelo poço 1-FL-1-P1 e mostrando o que cada um dos horizontes representa estratigraficamente.Fonte: Modificado de (TEIXEIRA, 2010).

Neste trabalho foi feita a interpretação de toda a Linha 0295-0009 (Figura 5), a partir da interpretação feita do trecho da Linha 0295-0009 que passa pelo poço 1-FL-1P1 (Figura 4). Usando o software GOCAD foi possível a visualização $3 D$ do cruzamento das seis linhas sísmicas com seus respectivos tamanhos e posicionamentos. Possibilitando fazer uma extrapolação mais segura dos horizontes sísmicos a partir da Linha 0295_0009 para as demais linhas, e dessa maneira mapear as estruturas da área alvo. Feita a interpretação da Linha 0295_0009 foi possível extrapolar os mesmos horizontes para a linha a que intercepta, a Linha 0295_0003. E assim para a Linha 02950007 e a Linha 02950008 que interceptam a Linha 0295_0003. E por final a interpretação da Linha 0295_0002 e da Linha 0295_0001 que interceptam a Linha 0292_0007 e a Linha 0295_0008, conforme mostrado na Figura 6. A Linha 0295-0007 é a mais representativa da área mapeada neste trabalho, pois 
mostra com mais clareza os refletores (Figura 7). Ela corta quase que perpendicularmente o Lineamento Transbrasiliano. Os refletores apresentam-se aparentemente horizontalizados, e não apresentam falhas bem marcadas. Uma feição interessante observada é o pinch-outdos refletores (acunhamento, terminação de uma camada geológica pela redução gradativa da sua espessura) nas laterais de um prováveldepocentro. Nessa região o embasamento atinge sua porção mais profunda em quase $2.500 \mathrm{~ms}$ (lembrando que a sísmica encontra-se em tempo) o que mostra claramente uma feição de um baixo estrutural.

\section{Modelagem Geológica Estrutural 2,5D}

Neste trabalho foi construído um modelo geológico estrutural 2,5D na Bacia do Parnaíba feito a partir da interpretação sísmica da Linha 0295-0007, mostrada no item anterior. Essa seção sísmica é a mais representativa e de melhor qualidade dentre as linhas sísmica interpretadas. O modelo geológico construído neste trabalho foi um 2,5D, ou seja, os pontos que formam os horizontes sísmicos da interpretação da Linha 0295-0007 foram repetidos ao longo do eixo horizontal a fim de formar uma estrutura que possibilite a visualização 3D das estruturas mapeadas na Linha 0295-0007 (Figura 8). A construção de um modelo estrutural da uma área de interesse pode ser feita através do fluxo de trabalho de modelagem estrutural "Building a Structural Framework" do software GOCAD. Outra forma de construção do modelo geológico estrutural corresponde à construção dos objetos geológicos que compõem o modelo estrutural (horizontes) manualmente no software GOCAD.Este foi o método utilizado neste trabalho.

$\mathrm{Na}$ Figura 8 destacam-se as formações de maior interesse da bacia. São mostrados os resultados, com destaque para a Formação Pimenteiras que é a principal unidade potencialmente geradora e para a Formação Cabeças que é a principal unidade potencialmente reservatório de hidrocarbonetos da Bacia do Parnaíba.

\section{Conclusões}

O cruzamento das seis linhas sísmicas mostrouse satisfatória visto que os refletores apresentavam continuidade entre as linhas. Ao todo, foram mapeados dez refletores a partir do topo da Formação Piauí até o que foi chamado de Embasamento. Com o mapeamento dos refletores podem-se observar algumas regiões que sugerem ser depocentros as quais devem estar relacionadas ao lineamento Transbrasiliano, principal lineamento regional desta bacia. $O$ modelo 2,5-D das estruturas geológicas existentes na área de estudo com destaque para as Formações Pimenteiras (unidade potencialmente geradora) e Cabeças (unidade potencialmente reservatória), pode contribuir para estudos no âmbito da geologia do petróleo na Bacia do Parnaíba.

\section{Agradecimentos}

A primeira autora agradece a SBGF (Brasil) pelo apoio financeiro. Agradecemos à ANP por disponibilizar os dados de poço e as linhas sísmicas da Bacia do Parnaíba. E também a REDE DE GEOFÍSICA DA PETROBRAS pelo suporte financeiro.

\section{Referências}

GÓES, A.M.O.; FEIJÓ J.F. Bacia do Parnaíba. Boletim de Geociências da PETROBRAS, Rio de Janeiro, v. 8 , n. 1, p.57-67. 1994.

TEIXEIRA, F. S. Análise estrutural e estratigráfica de feições geológicas através da interpretação de seções sísmicas e de mapas gravimétricos, na porção leste da Bacia do Parnaíba, PI. 2010. Trabalho de Conclusão de Curso (Graduação em Geologia) Universidade Federal do Rio de Janeiro, Rio de Janeiro, 2010.

GOCAD. Gocad 2.5.2. user'sguide. [S.I.]: GOCAD consortium, 2008.

COMPANHIA DE PRODUÇÂO E RECURSOS MINERAIS (CPRM). Serviço Geológico do Brasil. 2002. Disponível em http: // www. geoambiente. com.br/ website/cprmgeologico/viewer.htm. Acessado em 21 de Janeiro de 2005.

CUNHA, F.M.B. Evolução paleozóica da Bacia do Parnaíba e seu arcabouço tectônico. 1986. $107 \mathrm{f}$. Dissertação (Mestrado) - Instituto de Geociências, Universidade Federal do Rio de Janeiro, 1986.

SANTOS, V. H. Seqüênciassiluro-devoniana e eocarbonífera da bacia do Parnaíba, Brasil, como análogos para a explotação de hidrocarbonetos. 2005. 208f. Tese (Doutorado em Geociências) Universidade Federal de Pernambuco, CTG, Geociências, Recife, 2005.

CHIRA-OLIVA, P., CRUZ, J. C. R., MOURA, E., NEVES, $\mathrm{H}$., CARDOSO, M . 3-D velocity and structural modeling of Brazilian Amazonas paleozoic basin. In: GOCAD MEETING, 28., 2008, França.

VAZ, P. T.; REZENDE, N. G. A. M.; W. FILHO, J. R.; TRAVASSOS, W. A. S. Boletim de Geociências, PETROBRAS, Rio de Janeiro, v. 15, n. 2, p. 253-263, maio/nov. 2007.

DUARTE, O. O. Dicionário enciclopédico inglêsportuguês de geofísica e geologia. 2. ed. Rio de Janeiro: PETROBRAS, 1997.401p.

GÓES, A. M. de O; TRAVASSOS, W. A. S.; NUNES, K. C. Projeto Parnaíba: reavaliação da bacia e perspectivas exploratórias. Belém: Petrobrás, 1993. v.1. (Relatório interno). 

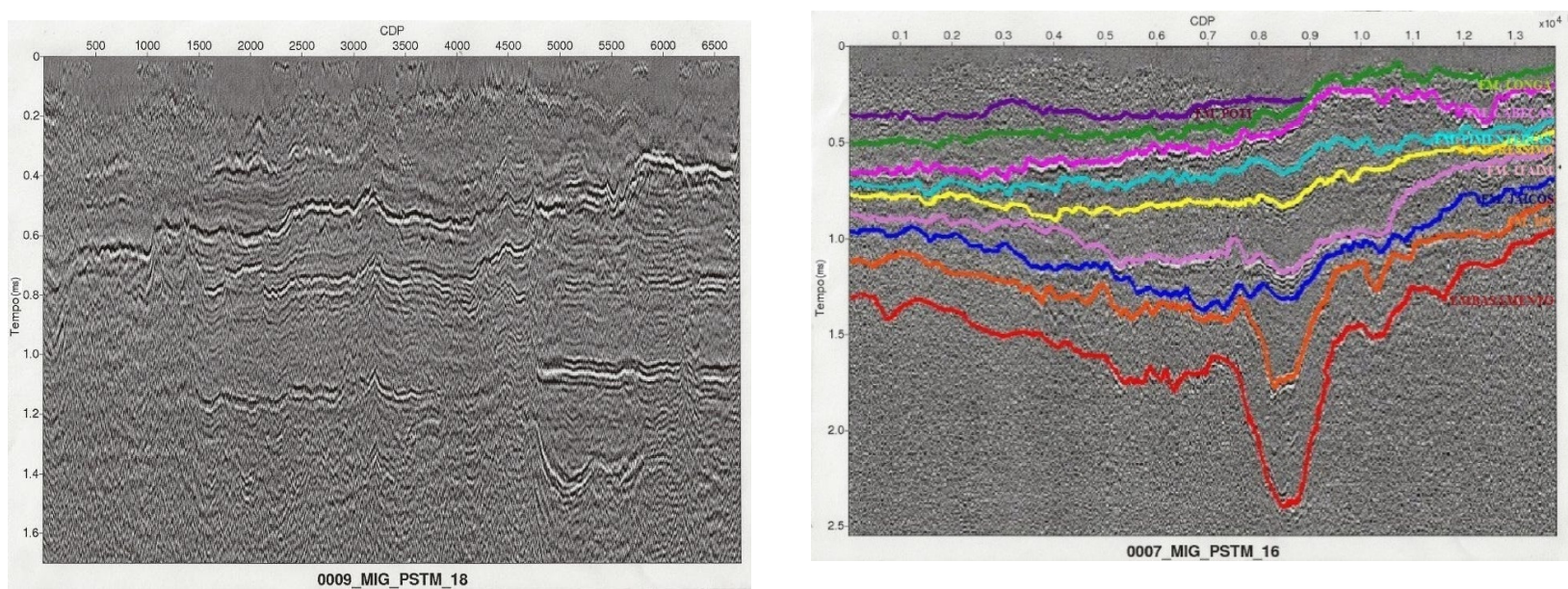

Figura 5:A esquerda, seção sísmica correspondente a Linha 0295-0009 completa, com traço em azul mostrando o trecho da seção que foi interpretado na Figura 4.A direita, a mesma seção mostrando os horizontes sísmicos interpretados e dizendo o que cada um dos horizontes representa estratigraficamente.
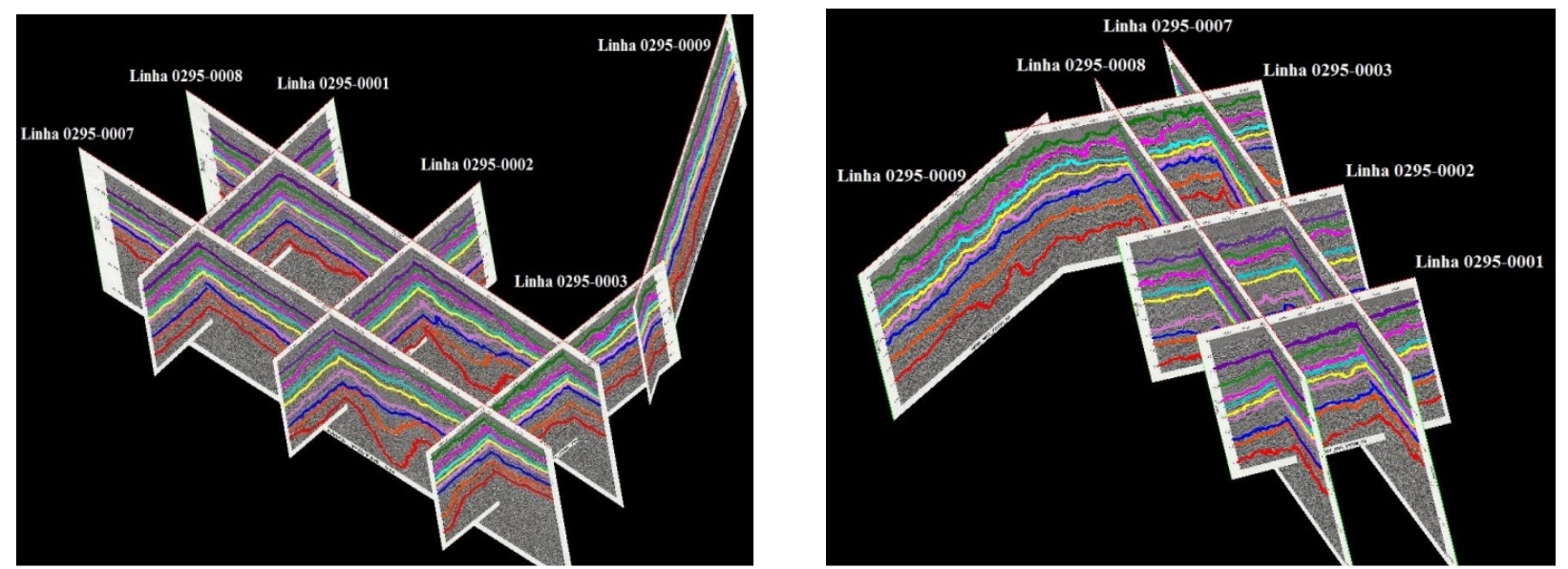

Figura 6 (esquerda e direita): Visualização da extrapolação dos horizontes sísmicos a partir da Linha 0295 _0009 para as demais linhas sísmicas interpretadas.
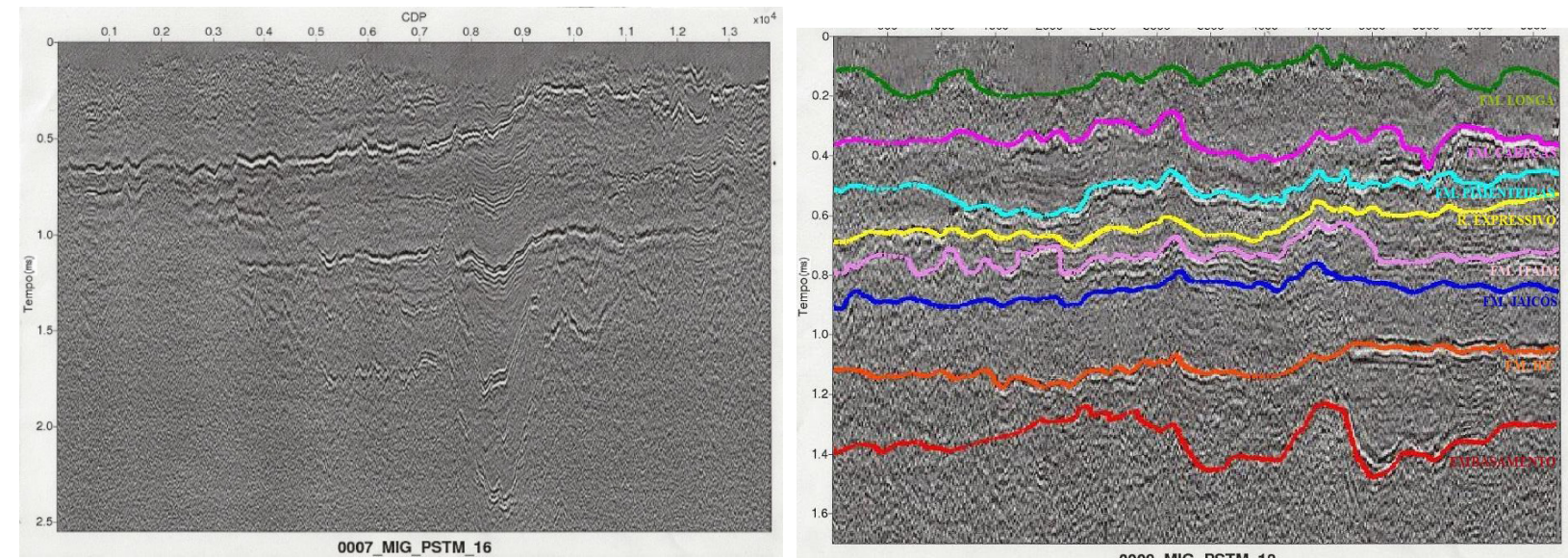

Figura 7: Esquerda, seção sísmica correspondente a Linha 0295-0007 completa. Direita, a mesma seção mostrando os horizontes sísmicos interpretados e dizendo o que cada um dos horizontes representa estratiqraficamente. 

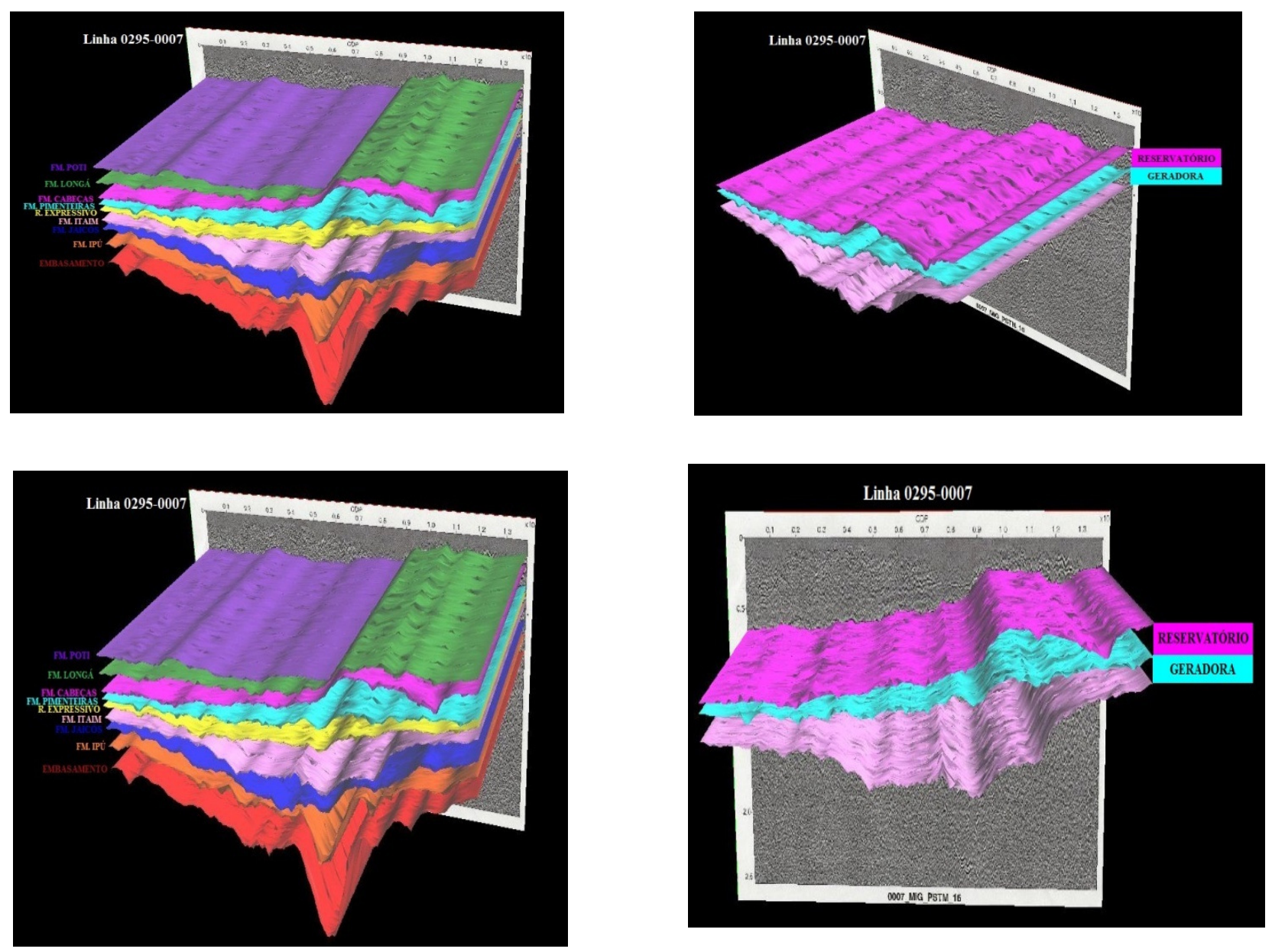

Figura 8: Acima à esquerda, Modelo Estrutural 2,5D construído a partir dos horizontes mapeados na Linha 02950007. Acima à direita, destaque lateral, abaixo à esquerda, destaque lateral e abaixo à direita, destaque frontal do topo e da base da Formação Pimenteiras (azul claro) que é a unidade potencialmente geradora da bacia e do topo e da base da Formação Cabeças (rosa-pink) que é a unidade potencialmente reservatória. 